\title{
Estudio sinecológico del bosque de roble-laurel-lingue del centro-sur de Chile
}

\author{
Synecological study of the roble-laurel-lingue forest in south-central Chile
}

C.D.O.: 182.3

\author{
CRISTINA SAN MARTIN ${ }^{1}$, CARLOS RAMIREZ ${ }^{1}$, HERIBERTO FIGUEROA ${ }^{1}$, NELSON OJEDA ${ }^{2}$ \\ ${ }^{1}$ Universidad Austral de Chile, Casilla 567, Valdivia, Chile. \\ ${ }^{2}$ Corporación Nacional Forestal, Manuel Montt 1151 - A, Temuco, Chile.
}

\begin{abstract}
SUMMARY
The mixed partially deciduous roble-laurel-lingue forest (Nothofago-Perseetum linguae) covered the Intermediate Depression in south-central Chile between the cities of Victoria and Puerto Montt. This primitive distribution area was strongly reduced to obtain agriculture and pasture lands. In order to promote the preservation of these endangered plant associations, a floristic and vegetational description was made on the basis of 52 vegetation samples, taken with the Braun-Blanquet phytosociological method in stands of the provinces of Cautín, Valdivia, Osorno and Llanquihue.

The flora have 158 species, $80 \%$ of them are native and the remaining $20 \%$ foreign. The most important trees are: Nothofagus obliqua, Luma apiculata, Persea lingue and Laurelia sempervirens. Among the lianen Chusquea quila and Lapageria rosea, stand out the former because its his high cover and the latter because its frequency. Rubus constrictus and Agrostis capillaris are important species belonging to the foreign elements introduced in these forest stands. Phanerophytes and hemicryptophytes dominate in the biological spectrum. The presence of therophytes with scarce cover, but with many species indicates xeric conditions. The forest is polystratified with a deciduous superior tree layer and a evergreen inferior tree layer. Furthermore, scrub, herb and moss layers are found. Eleven lianen species interconect these layers.

The ordering obtained with the principal components analysis, indicates the influence of many environmental factors on the microdistribution of the plant species. The most important are temperature and humidity. The phytosociological ordering separated the few primitive stands from the more intervened ones. Also those with ecotonal characters of the coihue-ulmo forest (Nothofago-Eucryphietum cordifoliae) of the "ñadi" soils from those of the temo-pitra forest (Blepharocalyo-Myrceugenietum exsuccae) of the "hualves". The floristic analysis and the structure of the stands indicates that the majority of them are secondary. However, abundant regeneration of the tree species was found. Finally, a possible secondary anthropogenic degradation is proposed and the conservation of these forest associations is recommended.
\end{abstract}

\section{RESUMEN}

El bosque de roble-laurel-lingue (Nothofago-Perseetum linguae Tomaselli, 1981) es una asociación mixta, parcialmente caducifolia, que ocupó toda la Depresión Intermedia del centro-sur de Chile, entre las ciudades de Victoria y Puerto Montt. Esta área original ha sido drásticamente reducida por la habilitación de tierras agrícolas y ganaderas. Para promover la conservación de esta asociación boscosa, amenazada de extinción, se hace una descripción florística y vegetacional de ella, sobre la base de 52 censos de vegetación levantados con la metodología fitosociológica de Braun-Blanquet, en rodales de las provincias de Cautín, Valdivia, Osorno y Llanquihue.

La flora de la asociación está integrada por 158 especies, de las cuales un $80 \%$ es autóctono y el $20 \%$ restante alóctono. Los árboles más importantes son Nothofagus obliqua, Luma apiculata, Persea lingue y Laurelia sempervirens. Entre las-trepadoras destacan Chusquea quila por su alta cobertura y Lapageria rosea, por su frecuencia. Rubus constrictus y Agrostis capillaris son importantes especies del elemento alóctono asilvestrado en los rodales. En el espectro biológico dominan fanerófitos y hemicriptófitos. La presencia de terófitos, aunque con escasa cobertura, demuestra condiciones xéricas. El bosque es pluriestratificado, con un estrato arbóreo superior caducifolio y uno inferior perennifolio. Además, se agregan estratos arbustivos, herbáceos y uno muscinal. Once especies de trepadoras conectan estos estratos. 
La ordenación realizada por el análisis de componentes principales señala la existencia de múltiples factores ambientales que condicionan la microdistribución de las especies, siendo los más importantes la temperatura y la humedad. La ordenación fitosociológica separó los pocos rodales prístinos de aquellos intervenidos, y de otros, ecotonales hacia el bosque de coihue-ulmo (Nothofago-Eucryphietum cordifoliae) de los ñadis, y hacia el bosque de temo-pitra (Blepharocalyo-Myrceugenietum exsuccae), de los hualves.

El análisis florístico y la estructura de los rodales indican que la mayoría de ellos son secundarios. Sin embargo, se constató una abundante regeneración de las especies arbóreas. Por último, se insinúa una posible dirección en la dinámica de degradación antropogénica, que actualmente afecta a esta asociación boscosa, cuya conservación se recomienda.

\section{INTRODUCCION}

El bosque parcialmente caducifolio de roble-laurel-lingue (Nothofago-Perseetum linguae Tomaselli, 1981) crecía abundantemente en Chile, entre Victoria y Puerto Varas, por la Depresión Intermedia (San Martín y Ramírez, 1987). Como esta asociación boscosa ocupaba los mejores terrenos agrícolas y ganaderos de la región centrosur de Chile, sus hábitats le han sido arrebatados por el hombre (Donoso, 1983). Por lo anterior, rodales de este bosque son escasos, y se encuentran muy alterados. Incluso, un gran número de ellos corresponden a renovales de poca edad (Ojeda, 1987).

El presente estudio es una descripción de esta asociación boscosa realizada sobre la base de censos fitosociológicos, levantados en rodales de las provincias de Cautín, Valdivia, Osorno y Llanquihue, en la Novena y Décima Región de Chile. El objetivo principal es dejar un testimonio de la estructura vegetacional y la composición florística de este bosque, para una futura regeneración artificial de él, ya que al no estar representado en el "Sistema Nacional de Areas Silvestres Protegidas por el Estado" (SNASPE), administrado por la Corporación Nacional Forestal de Chile (CONAF), está condenado irremediablemente a desaparecer.

\section{AREA DE ESTUDIO}

El bosque de roble-laurel-lingue era la asociación vegetal dominante en la Depresión intermedia de la región centro-sur de Chile (fig. 1). Los biótopos extremos o aquellos que desviaban del óptimo, en su enorme área, eran ocupados por otras asociaciones boscosas. Las depresiones del terreno con mayor humedad edáfica eran colonizadas por los bosques pantanosos de temo-pitra (Ramírez et al., 1990). En los ñadis, junto a la cadena de grandes lagos, con anegamiento invernal prolongado y se- quía estival, prosperaban bosques caducifolios de ñirre y perennifolios de coihue-ulmo (Ramírez et al., 1991). Por último, en los biótopos más temperados, de las riberas de los lagos, crecían rodales del bosque perennifolio de olivillo (Contreras, 1991), y en los más xéricos de la cuenca del río Bueno, del bosque esclerófilo de boldo (Ramírez y Romero, 1974).

El bosque de roble-laurel-lingue ha sido talado para habilitar tierras de cultivo y de pastoreo (Contreras y Ramírez, 1986). En su lugar existe hoy en día una formación vegetal artificial de parque, con grandes extensiones de praderas permanentes, en las cuales crecen ejemplares añosos de roble y de laurel (Ramírez et al., 1989).

El suelo ocupado por estas comunidades vegetales corresponde al tipo trumao, originado sobre cenizas volcánicas pleistocénicas (Weinberger y Binsack, 1970). Se trata de suelos profundos, ácidos, con mucha materia orgánica y alta capacidad de fijación de fósforo (Weinberger, 1971). El relieve posee suaves lomajes, lo que disminuye un poco el riesgo de erosión, al que son susceptibles. En la parte norte de su área, este bosque también ocupa suelos rojo arcillosos de la Cordillera de la Costa. El clima de la depresión intermedia ocupada por el bosque de roble-laurel-lingue es templado húmedo, con un marcado aumento de la precipitación hacia el sur (Di Castri y Hajek, 1976). La distribución de las lluvias tiende a concentrarse en invierno, dejando un corto período de sequía estival (Hajek y Di Castri, 1975). Este período seco, que varía entre uno y tres meses en el año, permite el desarrollo del roble (Nothofagus obliqua), como árbol caducifolio (Walter, 1970).

\section{MATERIAL Y METODO}

Aunque la metodología fitosociológica fue creada para estudiar la vegetación, diferenciando unidades en ella, también sirve para describir una asocia- 


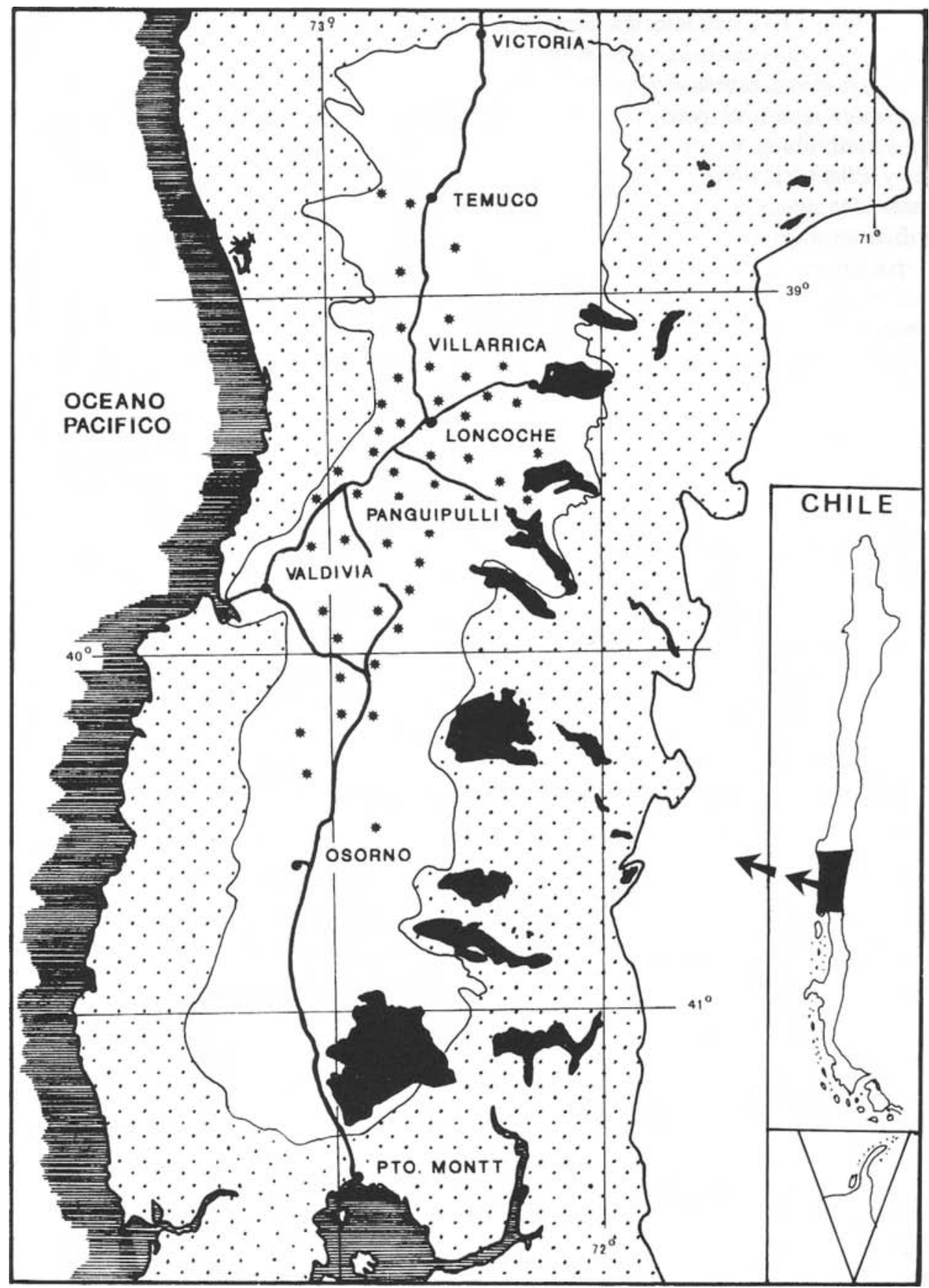

Fig. 1. Area de distribución (blanco) del primitivo bosque de roble-laurel-lingue, en el centro-sur de Chile. Los asteriscos señalan lugares de muestreo.

Primitive distribution area (white) of the roble-laurel-lingue forest in south-central Chile. The asterisks indicate samples sites.

ción vegetal (Knapp, 1984), tomando una gran cantidad de censos en toda el área de distribución de ella, con lo cual se logra una visión más objetiva de la estructura vegetacional y composición florística de la asociación (Kreeb, 1983).
Para este estudio se levantaron 52 censos de vegetación en otros tantos rodales, entre Temuco y Puerto Varas. Los censos se tomaron en áreas fisonómica, ecológica y florísticamente homogéneas (Ellenberg, 1956) superiores al área mínima 
determinada en uno de los rodales y que no superó los $140 \mathrm{~m}^{2}$. En cada censo se hizo una lista de las especies presentes, estimando luego, por simple apreciación visual, el porcentaje de cobertura de los individuos de cada una (MuellerDombois y Ellenberg, 1974). Para valores bajo $1 \%$ se usaron los signos "+" y "r" (cruz y erre) con sus significados tradicionales (Knapp, 1984). En cálculos posteriores, ellos fueron elevados a la unidad.

En cinco localidades del gradiente latitudinal norte-sur, se tomaron muestras de suelo hasta 30 cm de profundidad, a las cuales se determinó $\mathrm{pH}$ en agua, usando una relación suelo/solución de 1:2.5. El carbono total fue determinado mediante oxidación húmeda. La materia orgánica se calculó multiplicando el carbono total por el factor 2. El nitrógeno total se obtuvo según el método de Kjeldahl (Schlichting y Blume, 1966).

Con los censos se construyó una tabla fitosociológica inicial, que sirvió de base para el estudio florístico y vegetacional de la asociación. La flora del bosque de roble-laurel-lingue se estudió en la lista de especies vegetales de esta tabla fitosociológica inicial. En primer lugar se actualizó su nomenclatura y se determinó el carácter alóctono o autóctono de cada especie (Marticorena y Quezada, 1985). Luego se determinó la forma de vida de cada una, para confeccionar un espectro biológico de la asociación estudiada (Cain, 1950). Este se construyó con el número absoluto de especies de cada forma de vida, expresado en porcentaje y ponderando después la cobertura de los individuos de cada forma de vida (Hauenstein et al., 1988). Las plantas leñosas fueron diferenciadas en árboles, arbustos, trepadoras y parásitos, agregándose a esta forma de crecimiento las hierbas epífitas (Ramírez, 1988). Con ellas se estudió y graficó la estratificación del bosque estudiado.

En un análisis horizontal de la tabla inicial se estudió la contribución de cada especie en la vegetación del bosque de roble-laurel-lingue. Primero se determinó la frecuencia absoluta y relativa y el porcentaje de frecuencia. Luego se calculó la cobertura absoluta, promedio y relativa de cada especie. Por último, sumando la frecuencia y la cobertura relativas se determinó un valor de importancia (Wikum y Shanholtzer, 1978), que permite caracterizar objetivamente el bosque. En un análisis vertical de la tabla inicial se determinó el número de especies por censo, calculando su variación y el promedio de ellas por censo.
La tabla inicial ordenada por frecuencia sirvió como matriz de datos, para realizar un análisis de componentes principales, con el objeto de obtener una ordenación de especies y censos en un espacio de dimensiones reducidas (Orloci, 1975). Además, se realizó un análisis de similitud entre censos, usando el coeficiente de comunidad de Ellenberg (1956).

\section{RESULTADOS}

En los 52 censos de vegetación levantados, en otros tantos rodales del bosque de roble-laurellingue, se encontró un total de 158 especies vegetales, de las cuales 31 (19.6\%) son alóctonas y las restantes $127(80.4 \%)$ autóctonas. El promedio de especies por censo fue de 30.5 , con una desviación estándar de 5.6 y un $18.6 \%$ de variación.

Frecuencia. Como los rodales fueron seleccionados por la presencia de Nothofagus obliqua (roble), esta especie presentó un $100 \%$ de frecuencia, es decir, estuvo presente en todos los relevamientos. Con la misma alta frecuencia se presentó Lapageria rosea, el copihue. Altos valores de frecuencia presentaron, además, el helecho Blechnum hastatum (palmilla), Luma apiculata (arrayán), Rhaphithamnus spinosus (espino negro), Boquila trifoliolata (pilpil voqui), Chusquea quila (quila) y Aristotelia chilensis (maqui), todas especies nativas. Rubus constrictus (zarzamora), planta introducida, presentó un $71 \%$ de frecuencia, ya que fue censada en 37 oportunidades. La alta frecuencia de esta especie indica que los rodales censados presentan alto grado de intervención antrópica. Posteriormente, figuran las especies nativas Luzuriaga radicans (coralito), Laurelia sempervirens (laurel), Uncinia phleoides (clin-clin) y Berberis buxifolia (calafate), presentes entre 33 y 36 censos. Aquí también figura Agrostis capillaris, la chépica, especie introducida censada en 33 ocasiones, señalando también un estado de degradación de los rodales. Por último, Gevuina avellana el avellano chileno se presentó en 32 censos.

Cobertura. El mayor porcentaje de cobertura promedio lo presentó el roble $(70.7 \%)$, siendo la especie dominante en los rodales. Le sigue la quila, con un $38.9 \%$ de cobertura promedio. Esta especie heliófila se ve favorecida por el dominante caducifolio y por la reducción antrópica de los rodales. Los altos valores de cobertura de Nothofagus dombeyi, el coihue (16.6\%) se presentaron en lu- 
gares de suelos delgados, con características de ñadi. La chépica con un $14.7 \%$ y la zarzamora con un $13.1 \%$ de cobertura promedio indican alto grado de alteración de los rodales. Altos valores de cobertura promedio presentaron también Persea lingue, el lingue y el laurel, especies que integran el estrato arbóreo perennifolio, de menor altura.

El valor de importancia más alto (39.7) correspondió al roble, reflejando su alta frecuencia y cobertura. El segundo valor de importancia pertenece a la quila, con 18.8 , producto de su alta cobertura en los estratos arbustivos. En tercer lugar figura la zarzamora con un 7.1 de valor de importancia y en cuarto la chépica con 6.8. Ambas especies introducidas necesitan luz para su desarrollo y, por ello, reflejan alteración de los rodales. Entre las especies importantes figuran también tres árboles nativos, arrayán, lingue y laurel, con valores de 4.9,4.6 y 4.6, respectivamente.

Espectro biológico. Fanerófitos es la forma de vida más abundante en el bosque, con 81 especies y $51.9 \%$ del total. Importantes son los hemicriptófitos con 48 especies y $30.8 \%$ del total. Los terófitos, plantas anuales, presentaron 13 especies, señalando algún grado de sequía estival. Caméfitos y criptófitos tienen 7 especies cada uno (fig. 2).

Ponderando las coberturas de los individuos, los fanerófitos aumentan su importancia a $87 \%$. Los hemicriptófitos, aun cuando se mantienen en segundo lugar, redujeron su participación a 9.2\%. Los caméfitos participan ahora con $1.1 \%$. Criptófitos y terófitos presentan valores bajo la unidad. Dentro de los fanerófitos tienen importancia los mesofanerófitos y las lianas. De estas últimas se determinaron 11 especies. Aunque los nanofanerófitos (arbustos pequeños) presentan 23 especies, su contribución a la cobertura es baja.

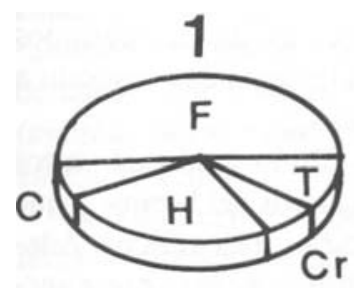

Fig. 2. Espectro biológico del bosque de roble-laurellingue. 1 = Número de especies, 2 = Cobertura. Formas de vida: $\mathrm{F}=$ Fanerófitos, $\mathrm{C}=$ Caméfitos, $\mathrm{H}=$ Hemicriptófitos, $\mathrm{Cr}=$ Criptófitos, $\mathrm{T}=$ Terófitos.

Biological spectrum of the roble-laurel-lingue forest. 1 = Number of species, $2=$ Cover. Life forms: $\mathrm{F}=$ Phanerophytes, $\mathrm{C}=$ Chamaephytes, $\mathrm{H}=$ Hemicryptophytes, $\mathrm{Cr}-$ Criptophytes, $\mathrm{T}=$ Therophytes.
Al comparar el origen de las distintas formas de vida del espectro se aprecia que la mayoría de las especies de malezas alóctonas se concentran en las formas de vida hemicriptofítica (hierbas perennes cespitosas y en roseta) y terofítica (anuales y bianuales), como lo muestra la figura 3 .

Estratificación. Las formas de vida descritas se disponen ocupando diferentes estratos, que hacen del bosque de roble-laurel-lingue una de las asociaciones boscosas mejor estructuradas del sur de Chile. El estrato arbóreo superior, que puede alcanzar $40 \mathrm{~m}$ de altura, está formado por el roble, caducifolio. Luego hay un estrato arbóreo inferior, siempreverde, donde abundan Mirtáceas. El estrato arbustivo es de altura y cobertura variable, dependiendo de la cobertura del dosel superior. Lo mismo sucede con los estratos herbáceo y muscinal. El esquema de estratificación de este bosque se expone en la figura 4.

Análisis de suelo. La muestra de suelo rojo arcilloso, correspondiente a la Serie Metrenco, obtenida en la provincia de Cautín, mostró bajos contenidos de materia orgánica (nitrógeno, relación carbono/nitrógeno), fósforo aprovechable y sodio (cuadro 1). Baja disponibilidad de nutrientes pre-

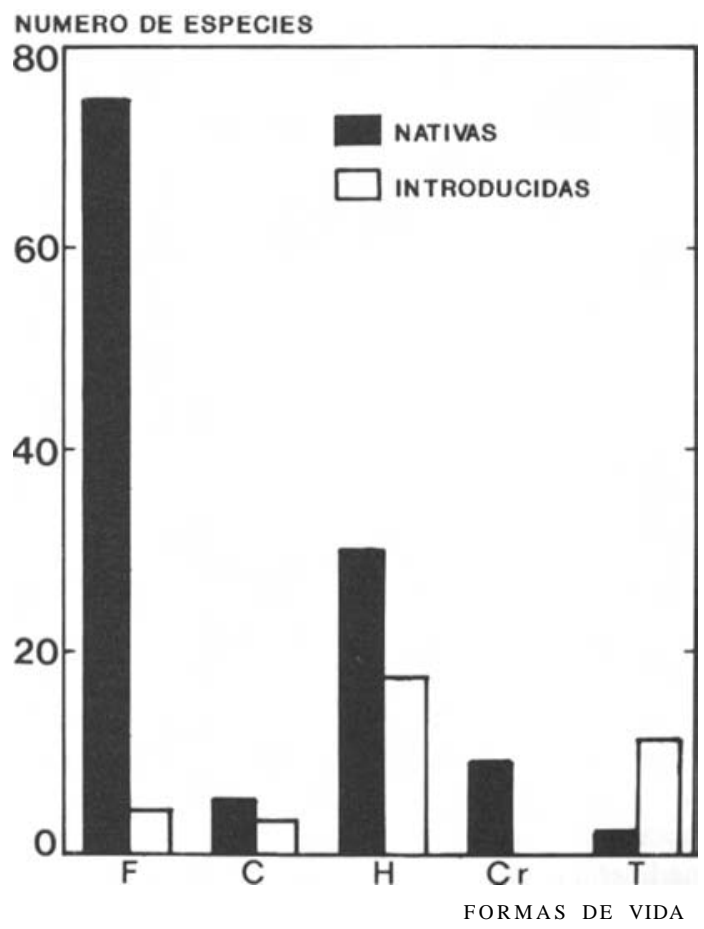

Fig. 3. Origen de las especies vegetales pertenecientes a cada forma de vida: $\mathrm{F}=$ Fanerófitos, $\mathrm{C}=$ Caméfitos, $\mathrm{H}=$ Hemicriptófitos, $\mathrm{Cr}=$ Criptófitos, $\mathrm{T}=$ Terófitos .

Origin of the plant species belonging to each life form: $\mathrm{F}=$ Phanerophytes, $\mathrm{C}=$ Chamaephytes, $\mathrm{H}=$ Hemicryptophytes, $\mathrm{Cr}=$ Cryptophytes, $\mathrm{T}=$ Therophytes 


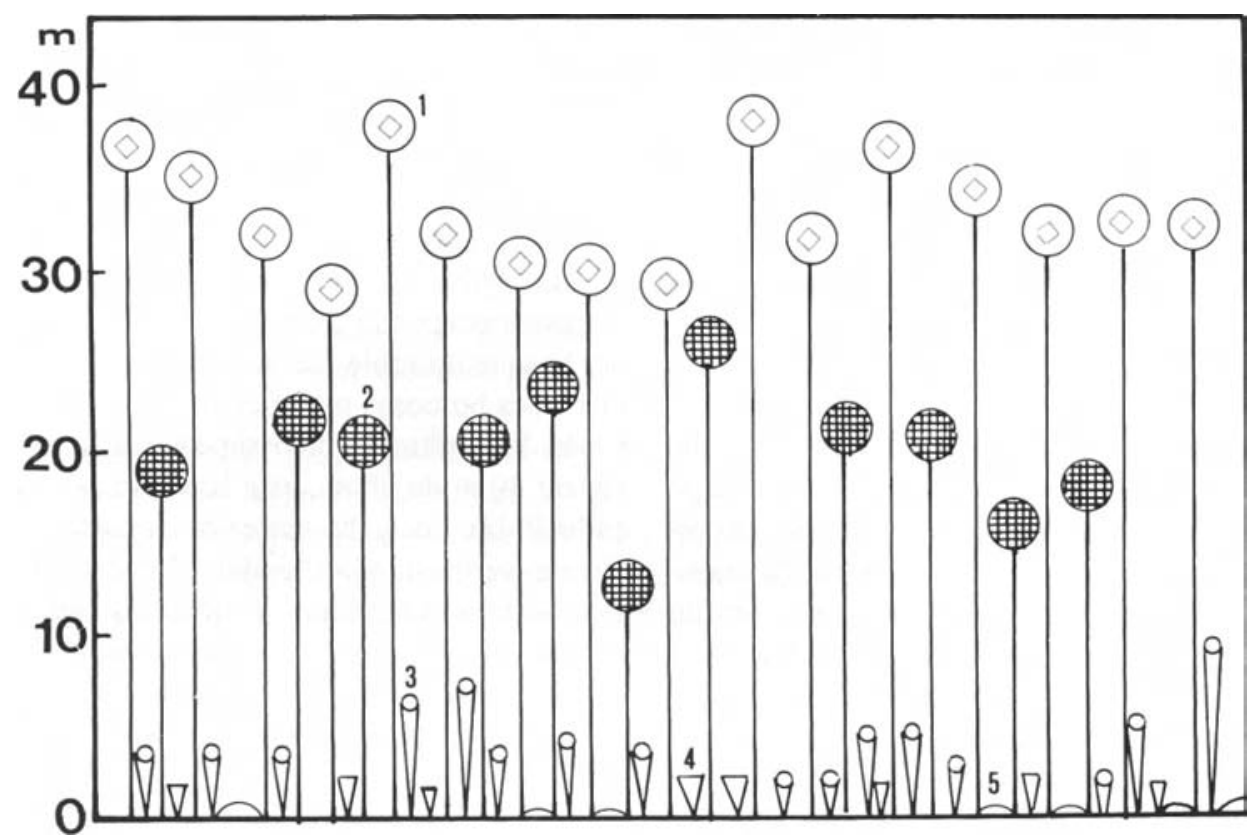

Fig. 4. Esquema de la estratificación del Bosque de Roble-Laurel-Lingue, usando los símbolos de Dansereau. 1 = Estrato arbóreo caducifolio, 2 = Estrato arbóreo inferior perennifolio, 3 = Estrato arbustivo, $4=$ Estrato herbáceo, $5=$ Estrato muscinal.

Outline of the stratification of the Roble-Laurel-Lingue forest, using the Dansereau symbols. $1=$ Upper tree summergreen layer, 2 = Lower tree evergreen layer, $3=$ Shrub layer, $4=$ Herb layer, $5=$ Moss layer.

sentó también el suelo de San José de la Mariquina, un trumao perteneciente a la Serie Pelchuquín. Por el contrario, los suelos trumaos, correspondientes a Los Lagos, Paillaco y Osorno, tienen alta disponibilidad de nutrientes, con un incremento, en el sector medio, del área de la asociación boscosa estudiada.

Ordenación estadística. Los 10 primeros componentes principales sólo explican el $60 \%$ de la variación, lo que indica que son numerosos los factores ambientales que inciden en la composición florística y distribución de los rodales analizados. Además, la pequeña diferencia existente entre la variación explicada por los distintos componentes señala que ellos tienen un peso parecido en su efecto sobre la vegetación. Esto mismo hace que la discriminación sea poco clara. La diferencia entre los primeros componentes es tan pequeña que es difícil interpretarlos como gradientes ambientales. Seguramente esta situación está relacionada con el alto grado de intervención, de naturaleza muy variada, evidenciada en los rodales.

La mayoría de las especies se presenta cerca de la intersección de los ejes, lo que indica cierta neutralidad con respecto a la temperatura y humedad, factores correspondientes a la ordenación de las especies en los dos primeros componentes. En efecto, observando la segregación de las especies en el primer componente, permite referir éste a un gradiente de temperatura que aumentaría hacia la izquierda (fig. 5). De la misma manera, el segundo componente podría corresponder a un gradiente de humedad del suelo, que aumentaría de arriba hacia abajo. De acuerdo a lo anterior, el plano de la figura puede dividirse en cuatro cuadrantes, de los cuales los dos superiores serían secos y los inferiores húmedos. De la misma manera, los cuadrantes de la izquierda serían cálidos y los de la derecha fríos. Los cuadrantes contiguos sólo difieren en la intensidad del gradiente, pero los opuestos son totalmente diferentes con respecto a estos dos factores ecológicos.

En el cuadrante seco y cálido se ubican varios arbustos que prosperan en claros del bosque y que forman matorrales secundarios más xéricos. Además de dos árboles termófilos: Aextoxicon punctatum, el olivillo y el lingue. En el cuadrante superior derecho, con condiciones secas/frías, se ubican varias malezas propias de praderas y del borde del bosque, entre ellas zarzamora y chépica.

En el cuadrante inferior izquierdo, que representa condiciones húmedo/cálidas, aparecen mu- 


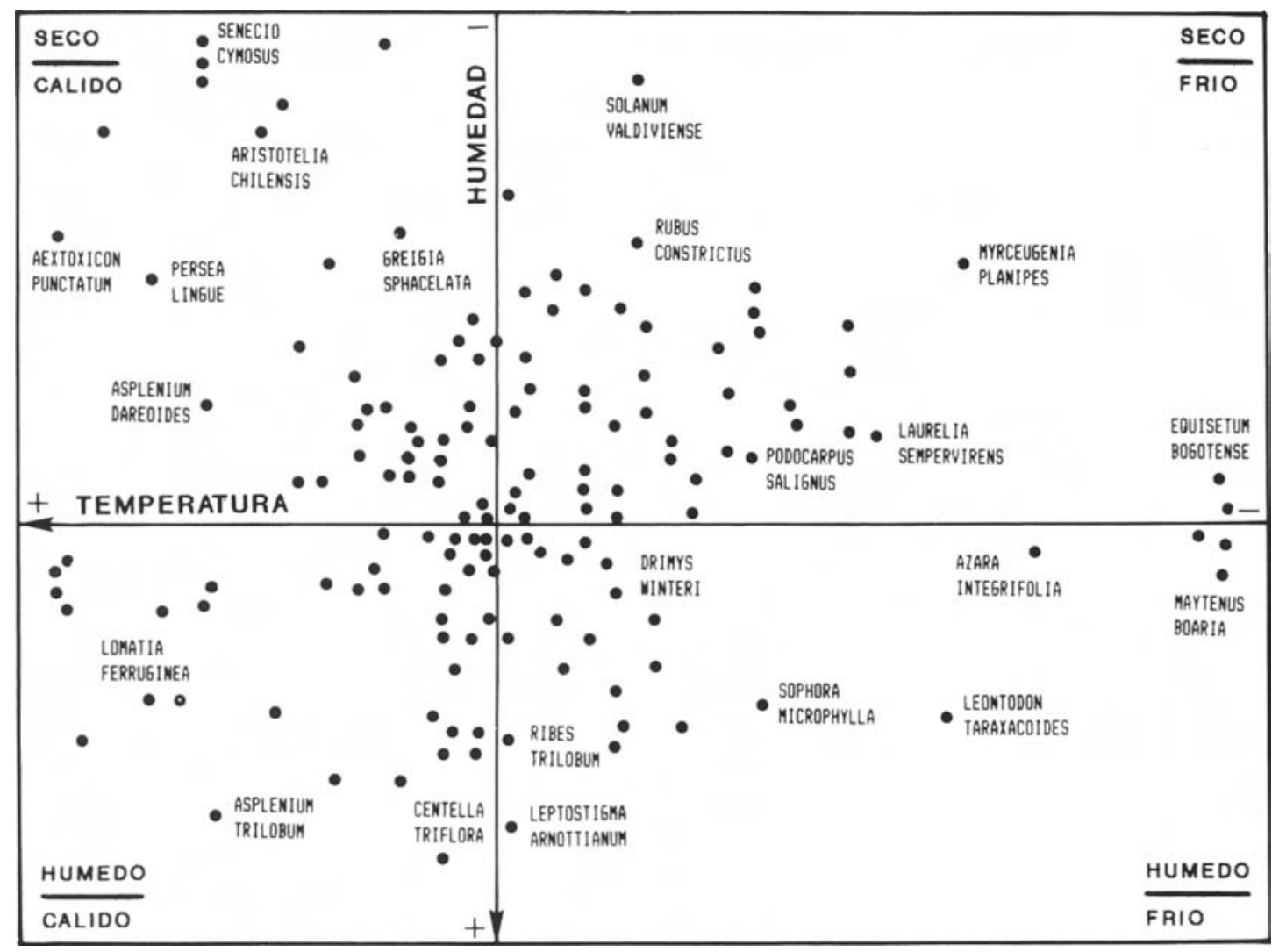

Fig. 5. Distribución de las especies en relación con los dos primeros componentes principales.

Distribution of the species in relation to the two first principal components.

chas especies nativas perennifolias que crecen en los estratos medios e inferiores del bosque; varias de ellas son propias de los bosques higrófilos templados valdivianos. Destacan coihue, Lomatia ferruginea, el romerillo, Amomyrtus meli (meli), entre los leñosos, y el culle azul e Hypolepis rugosula, entre las hierbas. Estas especies prosperan siempre bajo condiciones muy favorables. En el cuadrante húmedo/frío hay pocas especies y generalmente se trata de plantas de borde de bosque o de zonas ecotonales, tales como Maytenus boaria (maitén), Sophora microphylla (pelú) y Baccharis elaeoides (chilca).

En la figura 6 se dispusieron los censos en estos mismos cuadrantes. La mayoría de ellos se ubican cerca de la intersección de los ejes y, por lo tanto, no se desvían mucho con respecto de los dos factores analizados, con excepción de dos censos en el extremo izquierdo y otros dos en el extremo derecho del primer componente. En todo caso se observa una mayor segregación con respecto a los requerimientos térmicos que a los hídricos. Ade- más, en la ordenación de los censos no se aprecia formación de grupos.

Ordenación fitosociológica. Basados en la presencia o ausencia de las siguientes especies diferenciales: coihue, lingue y Ribes trilobum (zarzaparrilla), la tabla fitosociológica se ordenó en 6 grupos de censos (cuadro 2). El primer grupo (A) está constituido por censos levantados al noreste de Valdivia, excepto el censo número 12, que se levantó en Paillaco. En este grupo no están presentes los taxa diferenciales nombrados y, en cambio, dominan zarzamora, laurel y chépica, en frecuencia y cobertura. En el segundo grupo (B) el taxón diferencial fue la zarzaparrilla y reúne los censos que se levantaron cerca de Los Lagos y en San José de la Mariquina. Entre los taxa asociados positivamente a la zarzaparrilla figuran laurel y chépica. Al igual que el taxón diferencial, esta última especie prolifera óptimamente en lugares alterados. Otros taxa que se destacan en este grupo por su alta frecuencia son: clin-clin, coralito y Nertera granadensis (rucachucao). 


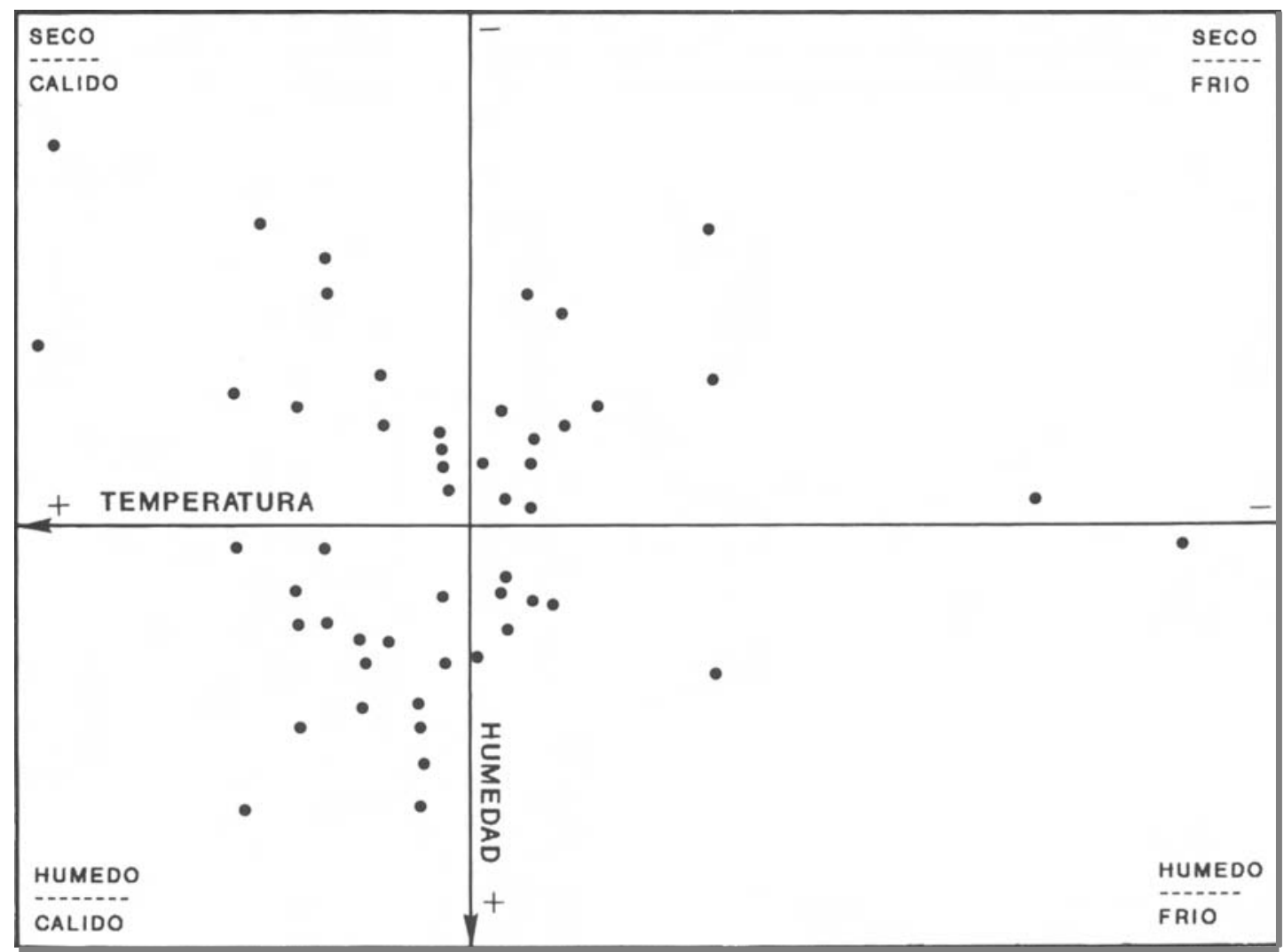

Fig. 6. Distribución de los censos de vegetación en los dos primeros componentes principales.

Distribution of the vegetation samples in the two first principal components.

\section{CUADRO 1}

Propiedades físico-químicas de los suelos en el área de distribución del bosque de roble-laurel-lingue Physico-chemical properties of the soils in the distribution areal of the roble-laurel-lingue forest

\begin{tabular}{|lccccc|}
\hline Propiedades/Localidades & Temuco & San José & Los Lagos & Paillaco & Osorno \\
\hline pH (1:2,5 en agua) & 5,8 & 5,3 & 6,2 & 6,2 & 5,2 \\
Materia orgánica & 9,23 & 17,44 & 10,54 & 26,83 & 33,59 \\
N total (\%) & 0,560 & 0,683 & 0,599 & 1,064 & 1,400 \\
Relación C/N & 9,55 & 14,80 & 10,22 & 14,62 & 13,91 \\
P aprovechable (ppm-Olsen) & 5,0 & 9,9 & 5,8 & 11,6 & 28,1 \\
K intercambiable (ppm) & 241,8 & 222,3 & 475,8 & 191,1 & 335,1 \\
Na intercambiable (meq/100) & 0,13 & 0,20 & 0,35 & 0,29 & 0,34 \\
Ca intercambiable (meq/100) & 8,83 & 2,75 & 5,42 & 23,33 & 12,50 \\
Mg intercambiable (meq/100) & 1,88 & 1,12 & 1,96 & 4,44 & 3,00 \\
Bases intercambio (meq/100) & 11,46 & 4,64 & 8,95 & 28,55 & 16,70 \\
\hline
\end{tabular}

En el tercer grupo de censos (C) los taxa diferenciales son lingue y zarzaparrilla y la mayor cantidad de estas parcelas se distribuye en el norte de la región estudiada. De este conglomerado, 5 parcelas corresponden a un mismo sector en las cercanías de Temuco y otra fue censada al norte de San José de la Mariquina. Las demás parcelas estaban localizadas en Paillaco y Los Lagos. Maqui participa caracterizando, en gran medida, los lugares muestreados. Este arbusto coloniza progresi- 


\section{CUADRO 2}

Tabla fitosociológica final ordenada.

Final ordered phytosociological table.

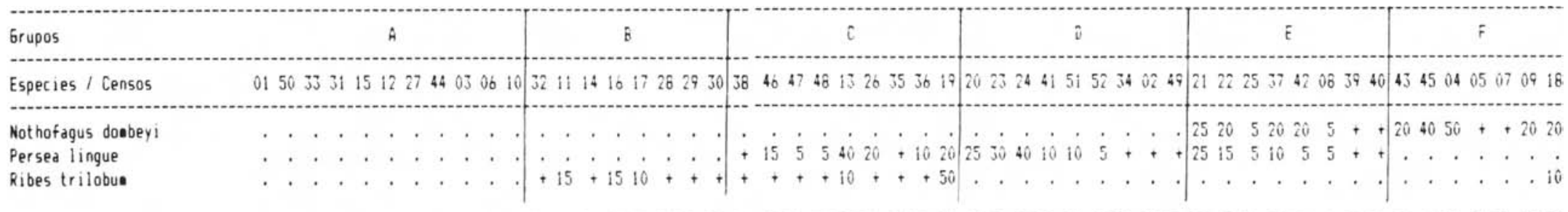

Nothofagus obliqua Chusquea quila

Rubus constrictus

Agrost is capillaris

Lued apiculata

Laurelia sempervirens

Rhaphithannus spinosus

Aristotelia chilensis

Gevuina avellana

Lapageria rosea

Blechnue hastatue

Boquila trifoliolata

Aextoxicon punctatua

Cissus striata

Luzuriaga radicans

Eucryphia cordifolia

Uncinia phleoides

Berber is darminii

Driays winteri

Lonatia dentata

Prunella vulgaris

Lonatia hirsuta

Podocarpus saligna

Rhannus diffusus

Oseorhiza chilensis

Nertera granadensis

Greigia sphacelata

Dactylis gionerata

Alstroemeria aurantiaca

Hydrocotyle poeppigii

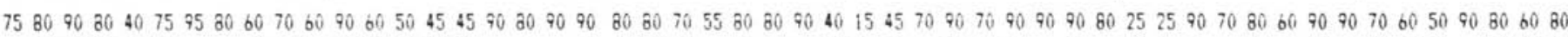

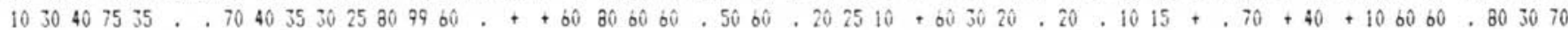
$+10++20254020++3010,15,++,+,++10+\ldots+, 201010,+10105++20+,+60606010+,+510+5$

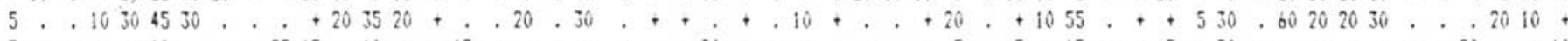
$5++++10+++2515 \cdot 10++15+++++++20+++++++5 \cdot 5+15++5+20+++++++20++10$

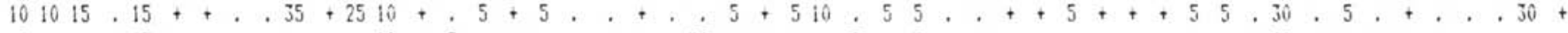
$55+++15++++++10+5++++++25++++15+5+++++,+++++40+++++++,+$ $30+++.15+++\ldots+\ldots+++10++++515++++405+\ldots++1052515+++\ldots++++\ldots+.++$

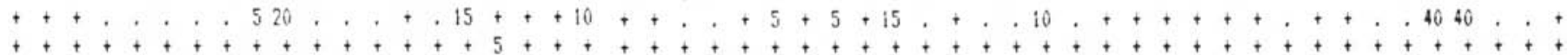

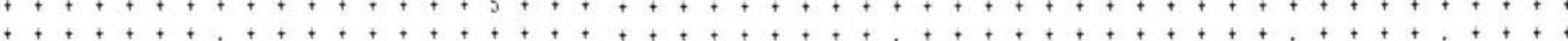

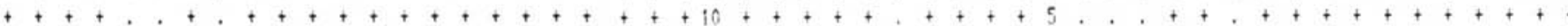

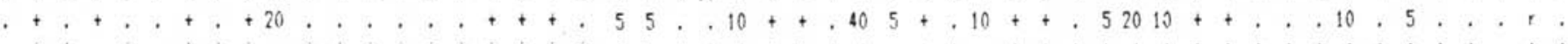

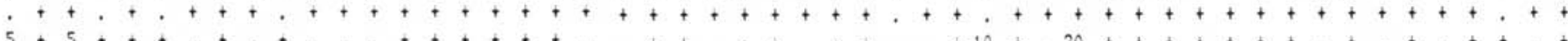

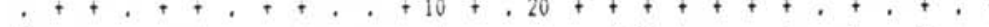
$+10, \ldots++,+,++,++10+,+5,5,5+4+50$

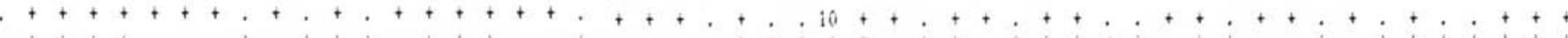

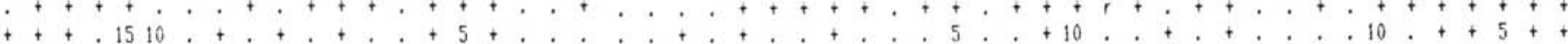

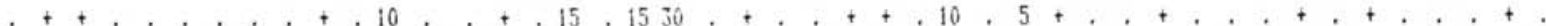

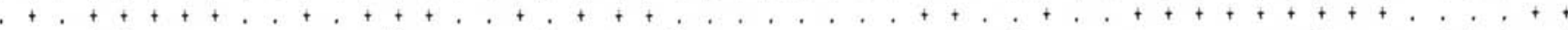

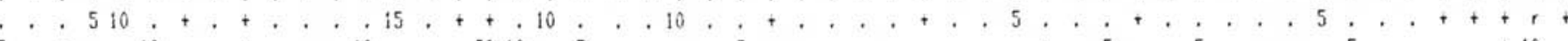

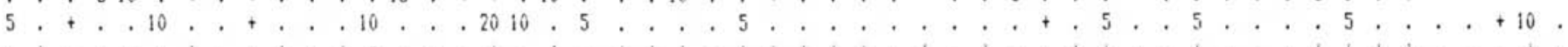

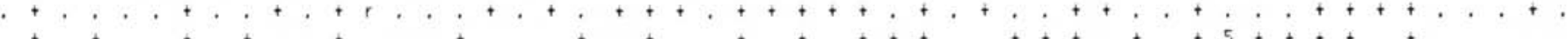

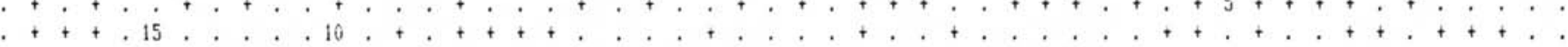

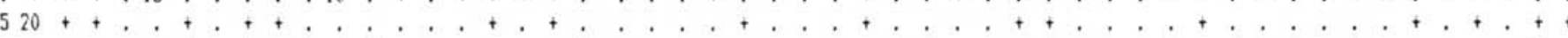

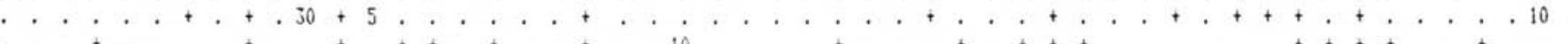

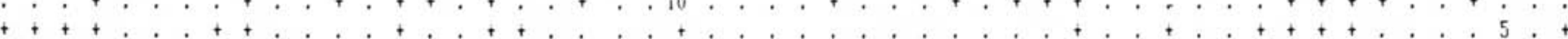




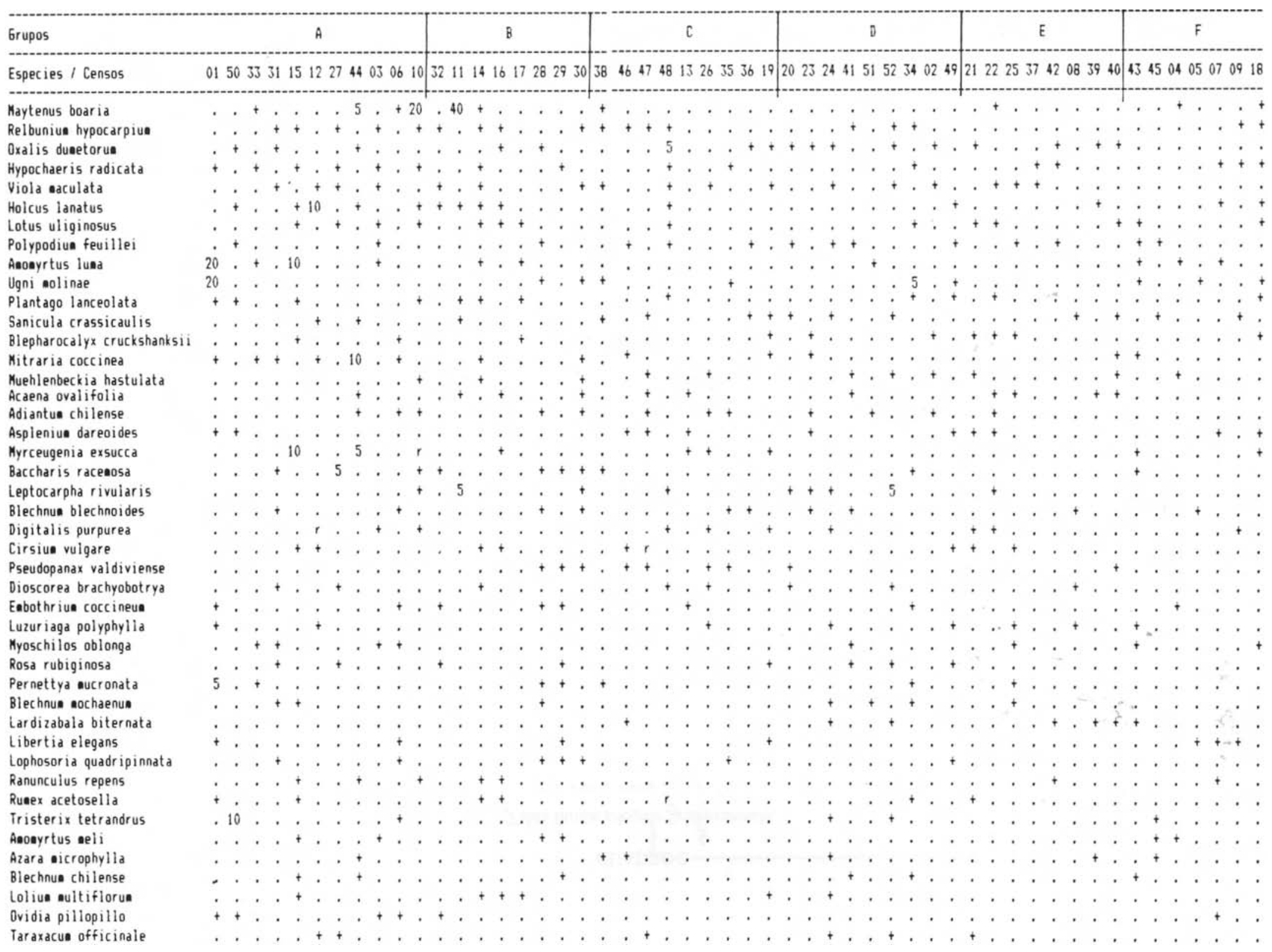


Codonorchis iessonii

Elytropus chilensis

Saraienta repens

Brous catharticus

Panicun capillare

Azara integrifolia

Hydrangea serratifolia

Hypolepis rugosula

Cynosurus echinatus

Satureja nultiflora

Azara lanceolata

Chloraea viridis

Fuchsia agellianica

Hyoenophyiliua krauseanue

Senecio chilensis

Stellaria cuspidata

irifoliue dubiue

Trifoliue pratense

Chusquea culeu

Conyza bonariensis

Crepis capillaris

Dendrolygotrichue dendroides

Fascicularia bicolor

Fragaria chiloensis

Hyaenophyilua plicatue

Leontodon taraxacoides

Libertia tricocca

Lobelia tupa

Luea gayana

filea eliliptica

Senecio yegua

Solanu valdiviense

Sonchus asper

Stachys grandidentata

Teline conspessulana

Uncinia erinacea

Además con "+" figuran las Especies siguientes (en los siguientes censos): Anthoxanthum odoratum (15), Asplenium trilobum (46), Baccharis elaeoides (31), Berberis buxifolia (03), Buddleja globosa (01), Cardamine nasturtioides (02), Carex fuscula (13), centella asiatica (34), Uncinia tenuis (19), Corynabutilon ochsenii (24), Cryptocarya alba (51), Ctenitis spectabilis (30), Cyperus eragrostis (10), daucus carota (37), Discaria serratifolia (04), Equisetum bogotense (20), Geranium robertianum (24), Gunnera tinctoria (43), Hymenophyllum pectinatum (01), Juncus bufonius (16). Leptostigma amottianum (08), Leucanthemum vulgare (03), Linum angustifolium (11), Lolium perenne (14), Lomatia ferruginea (05), Mentha rotundifolia (22), Misodendron linearifolium (48), Nothantera heterophylla (49), Oxalis araucana (51), Polygonum hydropiperoides (44), Ranunculus minutiflorus (44), Raphanus sativus (47), Rigodium implexum (51), Senecio cymosus

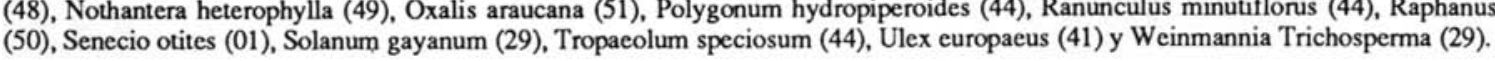


vamente los lugares alterados donde prolifera asociado a zarzaparrilla y también al lingue, que ha sobrevivido en escasas ocasiones a la tala selectiva. También abundan el pasto chépica, el arbusto Rhamnus diffusus (murta negra) y el árbol avellano.

En el cuarto grupo (D) desaparecen las 2 especies diferenciales tratadas en el grupo anterior, y en su lugar aparece el lingue. En este conglomerado se registraron 9 censos de vegetación, sin una clara uniformidad en su distribución. Se asocian positivamente con el lingue, la zarzamora, el olivillo y el maqui. El olivillo no es muy abundante en la comunidad, pero está asociado a lingue debido a que sus requerimientos ecológicos son similares. Los taxa mencionados son los únicos de este grupo que tienen valores de cobertura significativos, el resto de ellos participa en pocos censos de vegetación. Sólo Berberis darwinii, el michay fue encontrado en todos los censos del grupo.

El quinto grupo (E) está diferenciado por coihue y lingue, ambas con igual frecuencia y similares valores de cobertura. Estas caracterizan a 8 censos de vegetación, que se distribuyen en un gradiente latitudinal bien definido, existiendo censos en la localidad de Gorbea (provincia de Cautín) por el norte y Puyehue (provincia de Osorno) por el sur. Los taxa más importantes de este grupo de censos son chépica y zarzamora. Existen también especies que mantuvieron la alta frecuencia con que participan en los otros grupos, como ocurre con maqui, coralito, avellana, Prunella vulgaris (hierba mora) y Osmorhiza chilensis (apio del monte).

El último grupo (F) está representado por coihue $\mathrm{y}$, en menor grado, por el arbusto zarzaparrilla. La distribución de estos censos se circunscribe al área localizada entre San José de la Mariquina y la Cordillera de la Costa en esa latitud. Los censos que forman este grupo están caracterizados por una escasez de especies atribuible a las malas condiciones de suelo, con características de ñadi, que son típicas en sectores donde impera el coihue. Drimys winteri (canelo) aumentó aquí su frecuencia y cobertura con respecto a los otros conglomerados, posiblemente porque soporta mejor estas restricciones de suelo.

\section{DISCUSION}

Entre las especies más afines a la comunidad, figuran las trepadoras nativas copihue (Lapageria rosea), Boquila trifoliolata (pil-pil voqui), Cissus striata (voqui naranjillo) y quila. Oberdorfer (1960) relaciona la asociación que llamó Nothofago-Perseetum, con una gran variedad de arbustos y trepadoras, especialmente con el copihue. Los musgos lana del pobre y Dendroligotrichum dendroides (musgo pinito) son escasos en el bosque de roble-laurel-lingue, no así en el de olivillo (Lapagerio-Aextoxiconetum) de lugares más húmedos (Mora, 1986). Muy abundante en el sotobosque de estos rodales es palmilla, helecho que apareció en los diferentes lugares muestreados; comportamientos similares de esta planta, que indican una gran amplitud ecológica, fueron captados por Godoy et al. (1981). Otra especie destacable por su frecuencia es arrayán, reconocida como tal por Quintanilla (1981), quien describe a esta Mirtácea como una de las que se mezcla con el bosque de roble-laurel-lingue en la parte septentrional de su área de distribución. Alta participación en el estrato intermedio inferior tienen los arbustos espino negro y maqui, cuya abundancia es consecuencia de la alteración del bosque, y no refleja una condición original, en el primitivo bosque de roblelaurel-lingue (Figueroa et al., 1986). Las especies que están controlando la dinámica del bosque son aquellas invasoras de lugares alterados, como maqui, zarzamora y quila. Ellas inducen una presión selectiva que deja como remanente a una flora más reducida. En este fenómeno resultan poco afectadas las trepadoras (Torres, 1991).

El árbol caducifolio roble dominó ampliamente en cobertura, aventajando en el estrato superior a los otros taxa. Similares características de estos rodales fueron descritas por Schmithüsen (1956), reconociéndolo como bosque deciduo, estivifolio, de tierras bajas. En algunas ocasiones coihue lo acompaña en el dosel superior, especie que se desarrolla mejor en formaciones de ñadis, por lo que su presencia marginal indica suelos delgados con problemas de drenaje, que son condiciones límites para la sobrevivencia del roble (Ramírez et al., 1991). El lingue y el laurel caracterizan al bosque por su follaje siempreverde en el estrato intermedio, aunque el laurel alcanza alturas y diámetros mayores (Oberdorfer, 1960), la cobertura de ambas especies es similar. En la bibliografía se menciona a Eucryphia cordifolia (ulmo) como colonizadora en sitios parcialmente alterados en bajas elevaciones junto a roble. La diseminación de ambas es exitosa por las pequeñas diásporas aladas que poseen. Además, estas especies fácilmente pueden llegar a proyectarse $10 \mathrm{~m}$ por sobre 
las copas de los perennifolios, olivillo, lingue y laurel (Veblen y Ashton, 1978). Sin embargo, el ulmo presentó bajos valores de cobertura. Este árbol es usado como combustible casero y quizás por ello ha sido eliminado en forma selectiva. Bajos valores de cobertura tiene también la conifera mañío de hojas largas, aunque frecuentemente se concentra, asociado al roble y al olivillo (Ramírez et al., 1976).

La importancia del roble determina el carácter semicaducifolio de esta formación vegetal, que Schmithüsen (1956) denominó "frondosas caducifolias de la región templada", aunque en los estratos arbóreos inferiores aparece gran cantidad de árboles siempreverdes. Considerando lo anterior, Oberdorfer (1960) plantea que este bosque se podría denominar estivi-laurifolio, dando mayor importancia a las especies siempreverdes mesófilas, que siempre están presentes en forma abundante.

Las bambúceas del género Chusquea juegan un papel importante en la dinámica de regeneración y sucesión forestal de la pluviselva valdiviana (Müller-Using, 1973; Veblen et al., 1977). Quila está siempre presente en estos bosques, y en rodales que han sido fuertemente intervenidos, prolifera vigorosamente y se vuelve dominante en cobertura. Debido a sus características colonizadoras tiende a impedir o debilitar la regeneración arbórea (Gunckel, 1948; Veblen y Schlegel, 1982). Sin embargo, no forma matorrales secundarios en reemplazo del bosque de roble-laurel-lingue y, por el contrario, es desplazada de los murrales (Alstroemerio-Aristotelietum) que se forman en su reemplazo. Este comportamiento se debe a la mayor necesidad de humedad edáfica de la quila (Ramírez et al., 1984), que forma matorrales secundarios en reemplazo de los bosques de coihueulmo de los ñadis y de los de temo-pitra de los hualves, en hábitats con mayor humedad edáfica. Otra causa puede ser que los suelos trumaos son degradados por el cultivo o el pastoreo, al destruir el bosque. Las especies exóticas zarzamora y chépica han penetrado en los bosques de roble-laurellingue, llegando a poblar también algunos rodales remanentes. La dinámica de degradación del bosque de roble-laurel-lingue se esquematiza en la figura 7. Al cortar este bosque y no intervenir el suelo, se formaría un matorral de quila (Chusqueetum quilae), del cual se regeneraría el bosque original. Por el contrario, al talar o quemar el bosque y luego pastorear el lugar, se forman praderas permanentes de chépica y hierba de San
Juan (Hyperico-Agrostidetum), las que a largo plazo y por degradación del suelo son invadidas por un matorral de zarzamora (Alstroemerio-Aristotelietum Sin. Aristotelio-Rubetum), en los lugares más húmedos, y uno de chocho (TelinoAristotelietum), en los más secos.

La presencia de olivillo en el bosque estudiado es importante para dilucidar interpretaciones fitosociológicas. Según Murúa y González (1985), el bosque de olivillo de la base oriental de la Cordillera de la Costa no corresponde estrictamente a la asociación Lapagerio-Aextoxiconetum descrita por Oberdorfer (1960), sino más bien es una comunidad intermedia entre dicha asociación y el Nothofago-Perseetum. Esta descripción es bastante acertada considerando la abundancia de olivillo en esa comunidad, que ha sido descrita como una subasociación del bosque de olivillo, el Lapagerio-Aextoxiconetum Rigodietosum, diferenciándola en base a la participación del musgo lana del pobre y de los árboles roble y mañío de hojas largas. El primero (lana del pobre) es muy escaso en el Nothofago-Perseetum (Oberdorfer, 1960; Saravia y Uribe, 1991).

Los hemicriptófitos y los fanerófitos lideran en número de especies. Los caméfitos resultan menos afectados en sus valores de cobertura en relación a sus especies. No se registraron megafanerófitos en

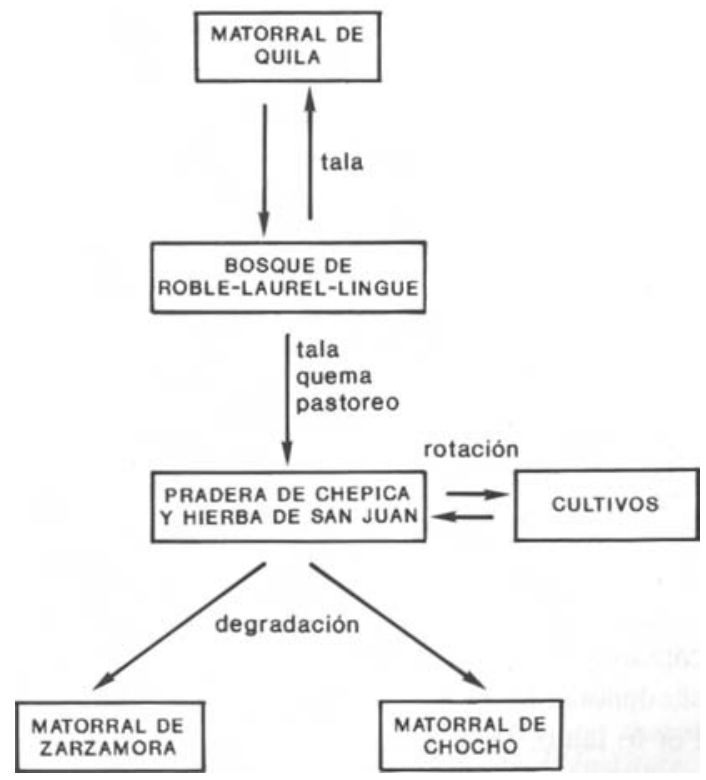

Fig. 7. Representación esquemática de la probable dinámica de degradación antrópica del Bosque de Roble Laurel - Lingue en el Centro-Sur de Chile.

Outline of the probable anthropogenic degradation dynamic of the Roble - Laurel - Lingue forest in South-Central Chile. 
la comunidad. Los mesofanerófitos son muy importantes por su abundancia en los estratos intermedio y superior. Entre los más típicos acompañantes de roble, según sus valores de importancia, tenemos las especies lingue, laurel, olivillo, ulmo y canelo. El coihue fue importante en sectores poco representativos de la comunidad. Schmithüsen (1956) también identificó a estas especies como típicas de la comunidad, omitiendo al canelo y agregando avellano y mañío de hojas largas. La participación de los nanofanerófitos es significativa en la comunidad, ya que su cobertura relativa es superada únicamente por los árboles dominantes. Una gran proporción de estos arbustos son taxa nativos, y de las especies introducidas, zarzamora está proliferando y expandiéndose hacia sectores más alterados, junto a Teline monspessulana (chocho) y Rosa rubiginosa (mosqueta) (Hildebrand, 1983).

La baja densidad que normalmente presentan los rodales de este bosque, así como la caducidad del follaje del dominante, permiten que exista un elevado número de trepadoras y lianas, formas de vida que caracterizan a estos bosques (Torres, 1991). Por otro lado, la alta densidad de especies mesofanerófitas perennes crea un ambiente húmedo bajo el dosel, justificando la abundancia de epífitos y de hierbas nemorales.

La mayoría de los grupos de censos obtenidos según los métodos tradicionales son poco definidos, en relación a su distribución geográfica. La presencia de coihue en la comunidad estudiada se ajusta a las clasificaciones de formaciones vegetales planteadas por Montaldo (1966) y Quintanilla (1981). En este análisis la presencia de coihue corresponde a una variante de zonas ecotonales con el sintaxón Nothofago-Eucryphietum cordifoliae de los ñadis (Ramírez, 1989). El canelo es el único elemento que muestra una adaptación a estas condiciones restrictivas de suelo, ya que posee una gran amplitud ecológica, figurando en la mayoría de las asociaciones boscosas de la región (Ferriere, 1982).

En el análisis fitosociológico tradicional se captaron subgrupos que difieren muy poco entre sí, denotando una alta homogeneidad florística. Por lo tanto, la vegetación estudiada se comporta como una asociación vegetal, con una significativa homogeneidad en su flora, pudiéndose clasificar fitosociológicamente como Nothofago-Perseetum linguae (Tomaselli, 1981), y los grupos de censos captados con las especies diferenciales correspon- den a zonas ecotonales o a estados de degradación. Entre los factores vegetacionales que incidieron en la formación de grupos de censos, se pueden mencionar la presencia de taxa ajenos a la asociación Nothofago-Perseetum, producto de una pequeña fracción de parcelas levantadas en zonas ecotonales, la presencia o ausencia de quila que influyó significativamente en los niveles de afinidad florística, corroborando su importancia en la asociación vegetal y el grado de alteración, reflejado en la abundancia de zarzamora y maqui.

El análisis de componentes principales explicó un porcentaje de variación bastante bajo, por los muchos factores ambientales que están participando en mayor o menor grado en la selección de las especies de la comunidad. A pesar de ello, se insinúa una respuesta de la vegetación a los factores climáticos. La ordenación de los censos obtenida con este análisis mostró una relación con la temperatura, lo que indica que en la región estudiada existe una respuesta definida de la vegetación al gradiente latitudinal. La asociación Nothofago-Perseetum fue definida por Oberdorfer (1960) como de carácter termófilo. Efectivamente, esta asociación ha sido destacada como típica de condiciones seco/cálidas en el centro-sur de Chile; mientras que más al norte prefiere aquellas más mésicas húmedo/templadas, propias de la precordillera andina (Ramírez et al., 1988). Desde un punto de vista climatológico, el roble juega un papel muy importante en el desarrollo de la comunidad, siendo una especie pionera que tolera extremos térmicos y que posibilita así el establecimiento de otros taxa (Weinberger, 1973). Esto indica que la diversidad forestal en la región es diferenciable por condiciones climáticas, más que por factores de suelo. La depresión ocupada por roble se caracteriza por la presencia de aire frío drenado de los Andes, y este árbol deciduo está bien adaptado a semejantes sitios (Mc Queen, 1977). El roble muestra también una clara tendencia continental, soportando un amplio espectro de temperatura (Klötzli, 1983).

Coincidente con la distribución del NothofagoPerseetum, se presenta una asociación vegetal de área muy fragmentada, el Blepharocalyo-Myrceugenietum exsuccae Oberdorfer 1960, bosque pantanoso de Mirtáceas que ocupa hondonadas con humedad edáfica y riberas de cursos de agua y que se confunden con los rodales semicaducifolios de roble-laurel-lingue (Ramírez et al., 1983). El ecotono entre estas dos comunidades es angosto, 
presentándose como una franja muy estrecha (Añazco et al., 1981), en la cual prospera pelú. Maytenus boaria (maitén), romerillo y canelo pasan del hualve a la zona ecotonal (Ferriere, 1982). La conífera mañío de hojas largas, siendo un taxón típico del bosque estudiado, sufre un enriquecimiento en estas zonas de transición (Ramírez et al., 1989).

Como se vio en los párrafos anteriores, el bosque de roble-laurel-lingue se encuentra, actualmente, como comunidades de segundo crecimiento y renovales, siendo muy escasos aquellos de condiciones prístinas originales, sin intervención humana. Como la mayoría de los Parques Nacionales de Chile están ubicados en regiones cordilleranas, este bosque de tierras bajas no encuentra protección en ellos. La única excepción la constituye el Monumento Natural del Cerro Nielol, en Temuco (provincia de Cautín, IX Región de Chile), ubicado en cordones costeros que penetran en la depresión intermedia (Ramírez et al., 1989), pero los bosques de roble-laurel-lingue conservados allí son de pequeña extensión y, además, se presentan fuertemente alterados (Hauenstein et al., 1988). Por lo anterior, se hace imprescindible realizar una prospección que permita ubicar rodales prístinos, que puedan ser conservados y protegidos para la posteridad.

La degradación del bosque de roble-laurel-lingue pone en peligro la existencia de la fauna nativa que encuentra refugio en él, y también la flora del sotobosque, que se desarrolla protegida bajo el dosel. Entre esta última, figuran dos arbustos con graves problemas de conservación: la Menta de árbol (Satureja multiflora) y la Huella chica (Corynabutilon ochsenii), especies que en la actualidad son muy escasas (Ross, 1987; Cifuentes, 1987). En igual forma posibilita el inicio de procesos erosivos irreversibles, que destruyen los suelos (Endlicher, 1991).

\section{CONCLUSIONES}

De los resultados presentados y discutidos en los capítulos anteriores se desprenden las siguientes conclusiones:

1. El bosque de roble-laurel-lingue corresponde a la vegetación climax zonal de la Depresión Intermedia de la región centro-sur de Chile. 2. Se trata de una comunidad pluriestratificada, cuyo espectro biológico es típico de asociaciones bos- cosas de climas templados. 3. Este bosque tiene una rica flora nativa, a la que se agrega un número importante de elementos introducidos, que indican alteración de los rodales. 4. Los factores determinantes de la microdistribución de las especies parecen ser de carácter térmico e hídrico. 5. Actualmente esta asociación boscosa está siendo eliminada por la habilitación de tierras agrícolas y ganaderas. 6. La mayoría de los rodales censados son de segundo crecimiento y representan diferentes estados de degradación de la comunidad original. 7. Actualmente esta asociación boscosa tiene escasa o casi nula representación en el Sistema de Areas Silvestres Protegidas por el Estado de Chile, lo que hace necesario tomar urgentes medidas para su protección. 8. Se sugiere la realización de un catastro que permita ubicar rodales en estado prístino para proceder a su conservación.

\section{AGRADECIMIENTOS}

Los autores agradecen el apoyo económico de FONDECYT, mediante el Proyecto de Investigación $\mathrm{N}^{\circ}$ 90-0067.

\section{BIBLIOGRAFIA}

AÑAZCO, N., MORAGA, M., RAMIREZ, C. 1981. "Distribución de las comunidades pratenses antropogénicas en un gradiente de inclinación en Valdivia, Chile", Agro Sur 9(1): 14-27.

CAIN, S.A. 1950. "Life forms and phytoclimate", The Botanical Review 16(1): 1-32.

CIFUENTES, R. 1987. Estudio autoecológico de Satureja multiflora (Lamiaceae) y su estado de conservación en Chile. Tesis, Escuela de Ingeniería Forestal, Universidad Austral de Chile, Valdivia, 57 pp.

CONTRERAS, D., RAMIREZ, C. 1986. "Evolución del paisaje vegetacional en la Décima Región de Chile". II Encuentro Científico Sobre el Medio Ambiente, Talca, Versiones Abreviadas 1: 96-100.

CONTRERAS, M. 1991. Análisis estadístico de la vegetación del Islote Rupanco (Osorno, Chile). Tesis, Escuela de Estadística, Universidad Austral de Chile, Valdivia, $165 \mathrm{pp}$.

DANSEREAU, P., LEMS, K. 1957. "The grading of dispersal types in plant communities and their ecological significance", Contr. de L'Institute Botanique de L'Université de Montreal, 71: 1-52.

DI CASTRI, F., HAJEK, E. 1976. Bioclimatología de Chile, Universidad Católica de Chile, Santiago, 128 pp.

DONOSO, C. 1983. "Modificaciones del paisaje chileno a lo largo de la historia". Simposio Desarrollo y 
Perspectivas de las Disciplinas Forestales, Valdivia 1: 365-438.

ELLENBERG, H. 1956. Grundlagen der Vegetationskunde. I. Teil Aufgaben und Methoden der Vegetationskunde. Ulmer, Stuttgart, $136 \mathrm{pp}$.

ENDLICHER, W. 1991. "Bodenerosion und Baldlandbildung in den Winterregen-Subtropen Chiles", Geographisches Rundschau 43(7-8): 438-445.

FERRIERE, F. 1982. Distribución, flora y ecología de los bosques pantanosos de Mirtáceas en la Región de Los Lagos, Chile. Tesis, Escuela de Ingeniería Forestal, Universidad Austral de Chile, Valdivia, $80 \mathrm{pp}$.

FIGUEROA, H., OTEY, M., RAMIREZ, C. 1986. "Un método para la ordenación de gradientes vegetacionales", Revista Sociedad Chilena de Estadística 3(2): 105-119.

GODOY, R., RAMIREZ, C., FIGUEROA, H., HAUENSTELN, E. 1981. "Estudios ecosociológicos en Pteridófitos de comunidades boscosas Valdivianas, Chile", Bosque 4(1): 12-24.

GUNCKEL, H. 1948. "La floración de la quila y el colihue en la Araucanía", Ciencia e Investigación Argentina 4: 91-95.

HAEEK, J., DI CASTRI, F. 1975. Bioclimatografía de Chile. Universidad Católica de Chile, Santiago, $214 \mathrm{pp}$.

HAUENSTEIN, E., RAMIREZ, C., LATSAGUE, M. 1988. "Evaluación florística y sinecológica del Monumento Natural Cerro Ñielol (IX Región, Chile)", Boletín Museo Regional Araucanía 3: 7-32.

HAUENSTEIN, E., RAMIREZ, C., LATSAGUE, M., CONTRERAS, D. 1988. "Origen fitogeográfico y espectro biológico como medida del grado de intervención antrópica en comunidades vegetales", Medio Ambiente 9(1): 140-142.

HILDEBRAND, R. 1983. "Die Vegetation der Tieflandgebüsche des südchilenischen Lorbeerwaldgebiets unter besonderer Berücksichtigung der Neophytenproblematik", Phytocoenologia 11(2): 145-223.

KLOETZLI, F. 1983. "Standortliche Grenzen von Fagaceen - ein Vergleich in beiden Hemisphären", Tuexenia 3: 47-65.

KNAPP, R. 1984. Sampling methods and taxon analysis in vegetation science. Dr. W. Junk Pub., La Haya, $370 \mathrm{pp}$.

KREEB, K.H. 1983. Vegetationskunde. Ulmer, Stuttgart, $331 \mathrm{pp}$.

MARTICORENA, C., QUEZADA, M. 1985. "Catálogo de la flora vascular de Chile", Gayana Botánica 42(1-2): 5-157.

MC QUEEN, D.R. 1977. "The ecology of Nothofagus and associated vegetations in South America", Tuatara 22(3): 233-244.

MONTALDO, P. 1966. "Estudios ecológicos básicos en la provincia de Valdivia, Chile. I. Las formaciones vegetales", Bol. Fac. Ciencias Agrarias, Univ. Austral de Chile 2: 3-18.

MORA, A. 1986. Estudios fitosociológicos en el bosque de olivillo (Lapagerio-Aextoxiconetum) de la Décima Región de Chile. Tesis, Escuela de Ingenie- ría Forestal, Universidad Austral de Chile, Valdivia, $85 \mathrm{pp}$.

MUELLER-DOMBOIS, D., ELLENBERG, H. 1974. Aims and methods of vegetation ecology. John Wiley \& Sons, New York, 547 pp.

MUELLER-USING, B. 1973. Untersuchungen über die Verjüngung von Nothofagus alpina (Poepp. et Endl.) Oerst. und ihre wichtigsten Begleitsbaumarten in der chilenischen Anden und Küstenkordillera. Disertación, Universidad de München, Munich, 229 pp.

MURUA, R., GONZALEZ, L. 1985. "Producción de semillas de especies arbóreas en la pluviselva valdiviana", Bosque 6(1): 15-23.

OBERDORFER, E. 1960. "Pflanzensoziologisches Studien in Chile. Ein Vergleich mit Europa", Flora et Vegetatio Mundi 2: 1-208.

OJEDA, N. 1987. Estudioflorístico y vegetacional del bosque de roble-laurel-lingue, en el centro-sur de Chile. Tesis, Escuela de Ingeniería Forestal, Universidad Austral de Chile, Valdivia, 122 pp.

ORLOCI, L. 1975. Multivariate analysis in vegetation research. University of Western Ontario Press, Ontario, $275 \mathrm{pp}$.

QUINTANILLA, V. 1981. "Carta de formaciones vegetales de Chile", Contribuciones Científicas y Tecnológicas Univ. de Santiago 11: 5-32.

RAMIREZ, C. 1988. "Formas de vida, fitoclimas y formaciones vegetales", El árbol... nuestro amigo 4(1): 33-37.

. 1989. "Past and present landscape and land use". En: T. Dillehay (ed.). Monte verde: A late pleistocene settlement in Chile. Smithsonian Institution Press, Washington \& Londres, pp. 53-85.

RAMIREZ, C., ROMERO, M. 1974. "Zur Verbreitung und Arrenzusammensetzung der südlichen BoldoWälder in Chile", Oberhessische Naturwissenschftliche Zeitschrift 41: 17-24.

RAMIREZ, C., FERRIERE, F., FIGUEROA, H. 1983. "Estudio fitosociológico de los bosques pantanosos templados del sur de Chile", Revista Chilena de Historia Natural 56(1): 57-72.

RAMIREZ, C., FIGUEROA, H., SAN MARTIN, J. 1988. "Comportamiento ecosociológico de los $\mathrm{No}$ thofagus sudamericanos", Monografías Academia Nacional Ciencias Exactas Físicas y Naturales 4: 5561.

RAMIREZ, C., STEUBING, L., ALBERDI, M. 1976. "La familia Hymenophyllaceae (Pteridophyta) en el fundo San Martín, Valdivia, Chile. I. Taxonomía y ecología", Medio Ambiente 2(1): 21-28.

RAMIREZ, C., FIGUEROA, H., CARRILlO, R., CONTRERAS, D. 1984. "Estudio fitosociológico de los estratos inferiores en un bosque de pino (Valdivia, Chile), Bosque 5(2): 65-81.

RAMIREZ, C., LABBE, S., SAN MARTIN, C., FIGUEROA, H. 1990. "Sinecología de los bosques de Boldo (Peumus boldus) de la cuenca del Río Bueno, Chile", Bosque 11(1): 45-56.

RAMIREZ, C., SAN MARTIN, J., HAUENSTEIN, E., CONTRERAS, D. 1989. "Estudio fitosociológico de la vegetación de Rucamanque (Cautín, Chile), Studia Botanica 8: 91-115. 
RAMIREZ, C., SAN MARTIN, C., FIGUEROA, H., MAC DONALD, R., FERRADA, V. 1991. "Estudios ecosociológicos en la vegetación de los ñadis de la Décima Región de Chile", Agro Sur 19(1): 34-47.

ROSS, C. 1987. Autoecología de Corynabutilon ochsenii Phil. (Malvaceae) en Chile. Tesis, Escuela de Ingeniería Forestal, Universidad Austral de Chile, Valdivia, $68 \mathrm{pp}$.

SAN MARTIN, J., RAMIREZ, C. 1987. "Fitosociología de los Nothofagus de la zona mesomórfica chilena", Bosque 8(2): 121-125.

SARAVIA, D., URIBE, F. 1991. Estudios sinecológicos estadísticos en el estrato herbáceo de un bosque de olivillo en Valdivia, Chile. Tesis, Escuela de Estadística, Universidad Austral de Chile, Valdivia, 211 pp.

SCHLICHTING, E., BLUME, E. 1966. Bodenkundliches Praktikum. Paul Parey, Hamburg, 321 pp.

SCHMITHÜSEN, J. 1956. "Die räumliche Ordnung der chilenischen Vegetation", Bonner Geographische Abhandlungen 17: 1-89.

TOMASELLI, R. 1981. "The longitudinal zoning of vegetation in the southern sector of the Andes", Studi Trentini di Scienze Naturali Acta Biologica 58: 471-484.

TORRES, V. 1991. Estudio ecosociológico de trepadoras en asociaciones boscosas de la Décima Región (Chile). Tesis, Escuela de Ingeniería Forestal, Universidad Austral de Chile, Valdivia, 100 pp.
VEBLEN, T. ASHTON, D. 1978. "Catastrophic influences on the vegetation of the Valdivian Andes, Chile", Vegetatio 36(3): 149-167.

VEBLEN, T., SCHLEGEL, F. 1982. "Reseña ecológica de los bosques del Sur de Chile", Bosque 4(2): 73115.

VEBLEN, T., ASHTON, D., SCHLEGEL, F. 1979. "Tree regeneration strategies in a lowland Nothofagus-dominated forest in South-Central Chile", Journal of Biogeography 6: 329-340.

WALTER, H. 1970. Vegetationszonen und Klima. Ulmer, Stuttgart, $244 \mathrm{pp}$.

WEINBERGER, P. 1971. "Charakteristische Eigenschaften und die Fruchtbarkeit südchilenischer Graslandböden auf vulkanischen Aschen", Der Tropenlandwirt 72: 51-71.

1973. "Bezienhungen zwischen mikroklimatischen Faktoren und natürlichen Verjüngung araukano-patagonischer Nothofagus-Arten", Flora 162: 157-179.

WEINBERGER, P., BINSACK, R. 1970. "Zur Entstehung und Verbreitung der Aschen Böden in Südchile", Der Tropenlandwirt 71: 19-31.

WIKUM, D., SHANHOLTZER, G. 1978. "Application of the Braun-Blanquet cover-abundance scale for vegetation analysis in land development studies", Environmental Management 2(4): 323329. 